\title{
Organizaciones autoconvocadas: construcción de lazos sociales urbanos en tiempos de restitución de lo público
}

\author{
Virginia Cáneva \\ (Laboratorio de Investigaciones de Lazos Socio-Urbanos, \\ Facultad de Periodismo y Comunicación Social, \\ Universidad Nacional de La Plata, Argentina)
}

Recibido: 11/4/2015

Aprobado: 15/6/2015

\begin{abstract}
Resumen. En los últimos años se observa en la Argentina un aumento tanto en la visibilidad política como en la participación, más o menos activa e institucionalizada, de organizaciones surgidas a partir de diversos intereses en el seno de la sociedad civil. La propuesta es analizar cómo construyen lazos intersubjetivos y urbanos los miembros de organizaciones de vecinos autoconvocados. En esta oportunidad, se presenta la construcción de un problema de investigación, su referente empírico y los modos de participación que las organizaciones promueven.
\end{abstract}

Palabras clave: organizaciones autoconvocadas / crisis / lazos sociales / comunicación / ciudad

\section{Self-Summoned Organizations: Construction of Urban Social Ties in Times of Restitution of Public Affairs}

Summary. Over the last years, an increase can be observed in Argentina in both the political visibility and the -more or less active and more or less institutionalized-political participation of organizations with different interests at the heart of civil society. This proposal aims at analyzing how members of self-summoned communitarian organizations built urban and intersubjective ties. We present here the construction of a research question, its empirical referent and the modes of participation that such organizations promote.

Key words: self-summoned organizations / crisis / social ties / communication / city 
De la institucionalidad a la autoconvocatoria vecinal: la construcción del objeto

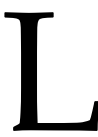

a problemática central propuesta en el trabajo de tesis docto$\mathrm{ral}^{1}$, que realizo en el marco del Doctorado en Comunicación de la Universidad Nacional de La Plata (Argentina), está atravesada por un interrogante embrionario que se pregunta por la manera de "estar juntos" de los sujetos en un contexto de crisis y de cambios en espacios urbanos. Puntualmente se hace referencia a la crisis de sentidos que se produce a partir de la transición de una manera moderna de vivir y pensar en sociedad hacia una posmoderna, que emerge cuando imaginarios que sostenían a nuestras sociedades han perdido, en parte, potencia instituyente. Asimismo, se alude a una segunda crisis vinculada con el agotamiento del modelo neoliberal, situación que se manifiesta en Argentina en el año 2001.
Desde este marco general, se propone indagar y analizar cómo construyen lazos intersubjetivos y urbanos los miembros de "Vecinos Autoconvocados de Villa Elisa" (en adelante V.A.V.E.) del distrito de La Plata, capital de la provincia de Buenos Aires. La conformación de este grupo se constituye a partir de un rechazo vecinal a una posible intervención directa en el espacio público, ligada a la construcción de la Autopista de Vinculación Presidente Perón. Se parte de considerar a la agrupación como un espacio de resurgimiento de prácticas cooperativo-solidarias, en tanto lugares de encuentro entre el individuo, la comunidad y el Estado, capaz de generar en el tejido social conciencia y participación ciudadana.

En los últimos treinta años se observa un aumento tanto en la visibilidad política como en la participación, más o menos activa e institucionalizada, de organizaciones surgidas a partir de diversos intereses en el seno de

1 La mencionada tesis, titulada “Crisis y reencuentros: la construcción de vínculos intersubjetivos en Vecinos Autoconvocados de Villa Elisa. Una mirada comunicacional sobre la recreación de lazos sociales-urbanos", es desarrollada en el marco de una Beca Doctoral otorgada por la Secretaría de Ciencia y Técnica de la Universidad Nacional de La Plata. Asimismo, las indagaciones que se realizan se desarrollan junto a los proyectos de investigación “Del ostracismo social al compromiso colectivo. Configuración y reconfiguración de espacios urbanos de participación ciudadana" (2010-2011), “Citas urbanas: construcción y regeneración de lazos socioculturales en la ciudad" (2012-2013) y “La ciudad y sus transformaciones. Estudio sobre la acción ciudadana en momentos de crisis eco-ambientales y/o político-sociales" (2014-2015), dirigidos por la doctora María Eugenia Rosboch, dentro del Programa de Incentivos a la Investigación y la Docencia del Ministerio de Educación de la Nación Argentina. 
la sociedad civil (Acuña y Vacchieri, 2007). Es precisamente en este marco de resurgimiento de formas de organización de la sociedad y de crisis que se propone reconocer qué lugar ocupan organizaciones como V.A.V.E para responder a tal inquietud, es necesario preguntarse: cuál es su presencia en el espacio público actual, qué rupturas y continuidades se pueden encontrar entre estas agrupaciones y los tradicionales espacios de construcción de vínculos urbanos como las instituciones barriales, los clubes sociales y las sociedades de fomento ${ }^{2}$.

Si bien en la actualidad podemos observar un resurgimiento en la participación de los vecinos en las instituciones tradicionales de su barrio, es innegable que el papel central que ocupaban ya no es el mismo (Cáneva y Mendoza, 2007). Los clubes sociales y deportivos nacen como institución junto al proceso de consolidación del Estado argentino, que en el caso de la ciudad de La Plata se vincula de manera directa con su fundación, en el año 1882.
Posteriormente, estas instituciones fueron construyendo su lugar de privilegio en la vida de cada uno de los barrios. En su etapa de esplendor (1930-1960) el club se presentaba como el escenario por el cual pasaba toda la actividad barrial: la diversión, el deporte, la cultura, la discusión y las fiestas. El momento de popularización de los clubes se relaciona con procesos históricos en los cuales el Estado y las instituciones en general gozaban de una solvencia y un prestigio que hoy parecen cuestionados o en crisis. Una época donde lo público y sus instituciones se conceptualizaban como propiedad comunal, contrastando con la actualidad donde "lo público" se establece en oposición a "lo privado". En un nivel barrial, estos valores redundaban en la ilusión y la confianza de todos en la posibilidad de trabajar juntos por el progreso y el mejoramiento de la calidad de vida de la comunidad. De esta manera, los clubes sociales constituían también un escenario privilegiado para el ejercicio de la participación comunitaria y ciudadana.

2 Desde el Laboratorio de Investigaciones en Lazos Socio-Urbanos se comenzó a indagar en la potencialidad que estos espacios barriales aún conservan para promover lazos sociales desde el año 2006, en el marco del proyecto "Los clubes sociales: hangares vacíos o potenciales espacios de reconstrucción y consolidación de vínculos urbanos" (2006-2009), dirigido por la doctora María Eugenia Rosboch e inscrito en el Programa de Incentivos a la Investigación y la Docencia del Ministerio de Educación de la Nación Argentina. Como producto de este trabajo se realizó, junto al licenciado Hernán Mendoza Jaufret la tesis "Clubes platenses al rescate de lo colectivo. Riesgos, desafíos y posibilidades de las instituciones barriales en la trama de la ciudad posmoderna". 
Entre las décadas de 1960 y 1970 el club y las instituciones barriales empiezan a transitar su etapa de deterioro, cuando en el país comienzan a implementarse políticas neoliberales en manos de gobiernos dictatoriales que contribuyeron al repliegue de la sociedad al ámbito de lo privado, a través de mecanismos fuertemente represivos. Como consecuencia de estas transformaciones culturales, sociales, políticas y económicas, los espacios públicos tradicionales retroceden. En este sentido, resulta pertinente indagar qué ocurre en la actualidad con los lugares que antaño canalizaban la demanda ciudadana y qué espacios son los que hoy la posibilitan.

Para comenzar a dar respuesta a esta inquietud se seleccionan como espacios de reflexión las organizaciones de vecinos autoconvocados, la importancia de estas organizaciones estriba en que implican otra relación entre lo público y lo privado. En consecuencia, ya no es la institución la que canaliza las necesidades barriales sino que la convocatoria surge de espacios autogenerados por la comunidad.

Por otra parte, y complementariamente, surgen una serie de interrogantes que buscan analizar la reconfiguración de espacios de participación ciudadana y de vínculos con el Estado. Se busca comprender, en- tonces, en qué medida estas agrupaciones pueden ser entendidas como espacios capaces de dar respuestas a las distancias que se abrieron entre los individuos y el Estado a partir de la crisis de representación que, este último, sufre por su pérdida de poder territorial con la penetración del capital transnacional ${ }^{3}$. Tal panorama conduce a replantear si es posible que la presencia de la agrupación en estudio, contribuya a generar tejido social de conciencia y participación ciudadana, observando al mismo tiempo qué vínculos entablan sus miembros con el Estado y las organizaciones sociales cercanas a ellos.

\section{Vecinos Autoconvocados de Villa Elisa: sus orígenes y antecedentes}

Los grupos de vecinos autoconvocados son organizaciones que emergen como forma de resistencia a políticas de intervención en el espacio público, con la intención no solo de participar en la protesta ciudadana sino también con la firme convicción de intervenir en la toma de decisiones. La aparición en nuestro país de esta forma de manifestación urbana se produce por el repudio a la instalación de corporaciones mineras en diferentes puntos del territorio nacional. Leandro Bonzi (2010) afirma que las primeras manifestaciones opositoras nacieron en 1997, en la

3 Véase Bauman (2005). Cap. III. “Después del Estado Nacional... ¿Qué?”, pp. 75-102. 
provincia de Catamarca. Posteriormente, menciona como fecha clave el año 2003, donde se desencadenó un período de intensa movilización social en la ciudad de Esquel, para evitar la instalación de una mina de oro. En la actualidad, existen decenas de asambleas de autoconvocados contra la minería que en algunos casos lograron trascender los espacios locales y constituirse en reclamos regionales, como por ejemplo la Unión de Asambleas Ciudadanas ${ }^{4}$. Otro movimiento que consiguió reconocimiento nacional fue la Asamblea de Vecinos de Gualeguaychu, que bajo el lema "No a las papeleras" sus integrantes denunciaron y resistieron la instalación de las pasteras de la trasnacional Botnia sobre el Río Uruguay, hasta llevar el conflicto a los máximos tribunales internacionales.

En el distrito de La Plata existen organizaciones vinculadas con la defensa del patrimonio como la organización "Defendamos La Plata"; los espacios verdes como "Bosque Alegre"; la seguridad vial, el desarrollo sustentable, la preservación del medio ambiente, como es el caso del "Foro Ambiental de Río de La Plata"; el tratamiento de los residuos que con la bandera de "No más Ceamce" impulsó la formación de la ya reconocida ONG "Nuevo Ambiente"; y la urbanización en los barrios de la periferia como la "Asamblea del Barrio San Carlos". Asimismo, surgen en la ciudad organizaciones que resisten los cambios en la traza urbana, como los vecinos de la localidad de Los Hornos que se encontraron bajo el lema "no al ensanche de la avenida 66", problemática muy cercana a la que analizamos en el marco de este trabajo.

Vecinos Autoconvocados de Villa Elisa $^{5}$ es una organización que surge en diciembre de 2010 y pone de manifiesto la movilización social que se produce a raíz de un proyecto de intervención en el espacio público relacionado con la posible construcción

4 La Unión de Asambleas Ciudadanas (UAC) "es un espacio de intercambio, discusión y acción conformado por asambleas, grupos de vecinos autoconvocados, organizaciones autónomas no partidarias ni vinculadas al aparato estatal y ciudadanos en general reunidos en defensa de los bienes comunes, la salud y la autodeterminación de los pueblos (...) nace con el propósito de articular y potenciar las diferentes luchas que en los últimos años han emergido en todo el país para repudiar el avance sistemático de los emprendimientos destructivos, y con la convicción de que la Consulta Popular y la autodeterminación de nuestras comunidades es la única vía para lograr un modelo de desarrollo regional sustentable, respetuoso del ecosistema, de las economías regionales y las culturas e identidades locales" (Perfil del Facebook de la Unión de Asambleas Ciudadanas).

5 Villa Elisa es una ciudad que pertenece al distrito de La Plata, se encuentra a doce kilómetros de la capital provincial y a treinta de la Ciudad Autónoma de Buenos Aires. Es posible ubicarla dentro de las ciudades intermedias, según los registros del Censo Nacional realizado en el año 2001 cuenta con 19643 habitantes. 
del tramo IV de la Autopista de Vinculación Presidente Perón sobre la calle 403 de esa localidad ${ }^{6}$. Las primeras aproximaciones muestran que lo que preocupa a los vecinos es la defensa de su territorio, su espacio público y el "estilo" de vida que ofrece su ciudad.

Un dato no menor es que la comunidad de Villa Elisa presenta una experiencia previa que impulsa la convocatoria para rechazar la traza de la Presidente Perón, ya que muchos de sus miembros participaron, en el año 2008, de los reclamos por el cierre de la "bajada" de la Autopista Buenos AiresLa Plata sobre la ruta provincial 19 de esta misma localidad platense, rechazo que con el tiempo dio origen a la consolidación de la asociación civil Vecinos en Defensa de Villa Elisa (VE.DE.VE) Dentro de la memoria colectiva también ocupa un lugar importante la Asamblea Popular de Villa Elisa, agrupación que se constituyó en enero de 2002.

Uno de los principales temas que ocupaba a VE.DE.VE era el rechazo a la habilitación de la bajada de la mencionada autopista. Las experiencias vividas por las personas integrantes de esta organización son insumos cotidianos en las prácticas de V.A.V.E. Se observa de este modo un entramado de vínculos que se tejen de manera continua y moldean la configuración de nuevas agrupaciones, teniendo en cuenta las experiencias previas.

Otra característica compartida por estas organizaciones es el hecho de

6 La realización de esta obra es impulsada por el Gobierno Nacional como continuación del Camino del Buen Ayre. Busca convertirse en el tercer anillo que rodea al área metropolitana de Buenos Aires con el fin de conectar catorce distritos bonaerenses. El proyecto, según se explica desde el Ministerio de Planificación de la Nación, tendrá una traza de 117 kilómetros divididos en cuatro tramos. El primero será de 23 kilómetros, comenzará en el Camino del Buen Ayre hasta la entrada en el partido de La Matanza. El segundo, comprenderá desde la localidad matancera de 20 de Junio hasta la ruta 53, el tercero hasta el cruce con la ruta provincial 58, y el último irá desde ese mojón hasta la autopista Buenos Aires-La Plata. El enlace vial proyectado tiene varias trazas posibles para su última etapa de ejecución, el Tramo IV. Dos de ellas, en palabras de los vecinos movilizados, afectarían la integridad del principal pulmón verde de la región, el parque Pereyra Iraola. Una tercera alternativa pasaría por la calle 403 de Villa Elisa. Esta calle nace en inmediaciones de la estación ferroviaria Pereyra, junto al terraplén del ramal que unía esa parada con la de Punta Lara, cruza los ramales vía Quilmes y vía Temperley del Ferrocarril Roca y llega al camino Centenario, a la altura del arco de Villa Elisa.

7 Esta asociación se crea en septiembre de 2009. Los objetivos principales que persiguen sus miembros son: "defender la calidad de vida de todos los habitantes de la localidad, promover y velar por la protección del medio ambiente y el desarrollo sustentable de la localidad y proporcionar un espacio amplio de discusión y estudio sobre todo asunto comunitario de interés público" (Perfil del Facebook de VE.DE.VE). 
que, frente a un fenómeno que genera desconfianza, malestar e incluso rechazo, los vecinos se reúnen, toman a su ciudad como objeto de discusión y desde allí planean diversas estrategias para expresar su disconformidad a la imposición de un nuevo orden. En este sentido, es posible afirmar que hay una necesidad de conservar la identidad barrial, el estilo de vida y la cotidianidad. Se recupera aquí la mirada de Leiras, para quien, "la actividad política de las organizaciones de la sociedad civil incluye tanto la promoción de cambios como la resistencia a los cambios" (Leiras, 2007, p. 45). Proponemos de este modo, recuperar una mirada que permita aproximarnos a las prácticas sociales en tanto procesos dialécticos que se juegan entre la conservación y la transformación.

La irrupción de los tres grupos en el escenario público de la comunidad fue producto de la iniciativa de los propios vecinos:

La Asamblea Popular de Villa Elisa alcanzó su nombre cuando un grupo de vecinos siguió hasta el centro de la plaza Luis Castels a Gustavo y Javiera (...) eran las seis de la tarde del primer viernes de enero (2002) cuando se plantaron en el centro de la plaza a tocar la cacerola para exigir a los políticos una sensibilidad diferente. A las nueve de la noche más de ochenta vecinos se habían sumado al grupo (Cossani y Duffard, 2007, p. 28).

Por su parte los integrantes de VE.DE.VE asumen que el inicio del reclamo por el cierre de la bajada de la autopista fue impulsado por la propia comunidad, en principio por los habitantes de Barrio Jardín, extendiéndose a otros sectores:

Yo pensaba, seguramente el Centro de Comercio va a ser el convocante, las instituciones. Pero, bueno, no pasaba nada, no pasaba nada. Entonces, dicen nos vamos a juntar y así fue que la gente del Club cedió el espacio y los vecinos propusieron: vamos a juntarnos a ver qué opina cada uno. Y se hizo una asamblea (Liliana, integrante de VE.DE.VE y V.A.V.E.).

Los vecinos toman la decisión de juntarse porque la convocatoria institucional no se producía.

Como se puede leer en apartados anteriores, las instituciones tradicionales eran el motor del encuentro barrial y la participación ciudadana, para Virginia, presidenta de VE.DE.VE, este es un síntoma de la crisis de las instituciones:

Los clubes han pasado por una gran crisis, a muchos les cuesta salir. Me parece que todavía están en crisis esas instituciones que han actuado en ese rol, pero hoy les cuesta porque es difícil que hasta se autosustenten. De hecho, en el tema de la autopista que dio nacimiento a VE.DE.VE los convocantes fueron socios del Club Barrio Jardín. Ahí fue la primera asamblea, pero después fue una institución que, si bien acompañó, no pudo ser la que lidera el proceso.

Al mismo tiempo, la entrevistada afirma que los clubes de la comunidad son reticentes a vincularse con proble- 
máticas sociales que llevan implícita una mirada política en sentido amplio.

V.A.V.E. surge unida al reclamo de la Asamblea del Parque Pereyra y Reserva de Biósfera, "espacio que se inició el 20 de febrero de 2010, cuando se toma conocimiento de la posible traza de la autopista Presidente Perón y cuyo objetivo de máxima es conformar un Comité de Gestión del Parque" (Toni, técnico vinculado a la Asamblea, durante el desarrollo de una charla informativa el 30 de noviembre de 2010, en la Facultad de Ciencias Naturales y Museo de la Universidad Nacional de La Plata. Sin embargo, en diciembre de 2010 los vecinos deciden separarse de aquella organización. Si bien esta división marca dos espacios territoriales y jurídicos diferenciados que comparten un mismo reclamo, también advierte sobre la configuración de dos maneras disímiles de organización política. En el caso del referente empírico de nuestro estudio, los vecinos refuerzan la idea de erigirse como una reunión de ciudadanos. Por su parte, la Asamblea del Parque Pereyra defiende los principios propios de este modo de organización horizontal y democrática de toma de decisiones, aspectos que si bien son recreados en V.A.V.E., confluyen en estrategias de acción diferenciadas.

Las continuidades entre estas organizaciones pueden encontrarse tanto en sus objetivos formales como en las herramientas de organización: proponen un espacio horizontal de discusión, ejercitando la toma de decisiones mediante asambleas participativas; son formaciones autoconvocadas; surgen a partir de una demanda ciudadana barrial y territorial y tienen como objetivo la reflexión y la proposición de nuevos proyectos de inclusión en el debate público.

\section{El territorio: un entramado de disputas sociales}

Los vecinos autoconvocados devienen en organizaciones territoriales, que se constituyen como actores en tanto partícipes de una disputa por la forma que adoptará su territorio tanto en términos materiales como simbólicos. En palabras de Pedro Pírez, los componentes sociales urbanos se fijan con base en la relación entre dimensiones sociales y territoriales:

Si bien los actores urbanos dependen de los procesos estructurales, el papel que juegan en la ciudad depende de la forma particular en que se organicen como unidades de acción y ello depende también de su relación con el territorio urbano (Pírez, 1995, p. 1).

La trama de la urbe se presenta, así, como una obra que si bien se basa en contradicciones estructurales, no parece estar determinada por ellas. Los diferentes actores cumplen un papel decisivo en la conformación de estas tramas: su desempeño dependerá en gran medida del nivel de organización y del poder de influencia que este colectivo logre capitalizar. 
De este modo, resulta indispensable poder dimensionar la problemática que dio origen a la conformación de V.A.V.E., atendiendo a cada uno de los sectores presentes. Se encuentran así actores locales que representan a la sociedad civil, nucleados en grupos de vecinos autoconvocados, al igual que en instituciones tradicionales como el Club del Barrio Jardín o el Centro de Comercio de Villa Elisa. Asumir, junto con Bonzi (2010), que el principal factor de adscripción al grupo autoconvocado es un territorio compartido permite advertir que la composición de los grupos deviene heterogénea en cuanto al poder adquisitivo de sus integrantes, sus niveles de instrucción, su vínculo con el problema por resolver, su actividad profesional, sus experiencias previas de participación, su ideología o militancia política. Esta heterogeneidad se manifiesta en V.A.V.E. en la pluralidad de actores que conviven en la organización: quinteros productores, propietarios que temen por la expropiación de sus viviendas, profesionales que aportan los conocimientos desde sus disciplinas: técnicos, abogados, médicos, economistas; militantes sociales que participan en diversas instituciones de la comunidad y antiguos vecinos que temen que la autopista rompa el paisaje que los vio nacer, crecer $\mathrm{y}$ formar sus familias.

Al mismo tiempo, la diversidad de actores que conforman esta disputa territorial se materializa en diferentes niveles de representación, haciéndose presente funcionarios públicos municipales, como el intendente Pablo Bruera, el secretario de la Unidad Ejecutora de la Agencia Ambiental de la Municipalidad de La Plata, Sergio Federovisky, el delegado municipal de Villa Elisa, Darío Romero Klein, y concejales de diversos partidos políticos. Participan, además, figuras con fuerte presencia en instancias de toma de decisiones a escala provincial, como el juez de Quilmes, Luis Armela (responsable de hacer lugar al recurso de amparo que impide avanzar con las obras), el fiscal de Estado, Ricardo Szelagowski, y el defensor del pueblo bonaerense, Carlos Bonicatto. En este grupo también encontramos a los legisladores y organismos de órbita bonaerense como el Organismo Provincial para el Desarrollo Sostenible. En el nivel de pertenencia nacional y como promotor de la obra se encuentra el Ministerio de Planificación, representado por Raúl Arias Saisi, jefe del Distrito 1 de la Dirección de Vialidad Nacional.

Asimismo, intereses privados y empresariales poseen una gran influencia en la realización de la obra, personificados principalmente en las firmas adjudicatarias para cada uno de los tramos de construcción: Iecsa, Perales Aguilar, CPC, Electroingeniería, Contrera Hnos., Cartellone y el Grupo Petersen. Según consta en los pliegos de licitación, la adjudicataria para la construcción del Tramo IV es una unión transitoria de empresas integrada por José Cartellone Construcciones 
Civiles S. A. y Petersen Thiele y Cruz S. A., que ya instaló un obrador en ruta 36 y calle $403^{8}$.

A este entramado de relaciones políticas, sociales y económicas debe sumarse que el desarrollo del proyecto vial Autopista de Vinculación Presidente Perón se encuadra en un contexto de trasformaciones sobre la región, donde se destaca la planificación y ejecución de obras como la construcción de una terminal de contenedores portuaria en la ciudad de Berisso, la ampliación de la traza de la autopista Buenos Aires-La Plata, la construcción de un cableado de alta tensión entre los partidos de Ensenada y Berazategui y el restablecimiento del aeropuerto local en la ciudad capital. Al mismo tiempo, otro factor que incide en la reorganización territorial de toda la zona son las inversiones inmobiliarias, que impulsaron al gobierno municipal a presentar un conjunto de ordenanzas que introdujeron importantes cambios en el Código de Ordenamiento Urbano y en el Código de Edificación. Ambas modificaciones se aprobaron en abril de $2010^{9}$, después de varios meses de agitadas discusiones, donde surgieron voces opositoras provenientes de diferentes sectores de la ciudadanía. En este marco, los propios vecinos afirman que "es importante una revisión del territorio y lo que significa para cada uno de los actores" (Toni, integrante de la Asamblea Parque Pereyra y Reserva de Biósfera).

\section{Estrategias de acción: identidad grupal y modos de participación}

En líneas generales, los vecinos identifican sus perfiles de acción bajo dos rótulos que conciben como diferenciados pero complementarios al mismo tiempo. "Los vecinos debemos combinar estrategias jurídicas y políticas. Es una lucha que hay que atacar por varios frentes", afirmaba un representante del grupo en la asamblea de constitución de V.A.V.E., el 11 de diciembre de 2012. Si bien se continúa con esta clasificación propuesta por el colectivo, las actividades son reagrupadas en diversas estrategias, teniendo en cuenta su objetivo, el impacto esperado y los medios

8 Véanse el diario La Nación: “La competencia entre los constructores viales David y Goliat”, publicada el 13 de diciembre de 1998; el portal de noticias lapoliticaonline.com: "Autopista Perón: Cinco años de anuncios y ni un metro construido", y el diario El Día, de La Plata: "Cinco propuestas y un final incierto", las dos últimas del 28 de noviembre de 2010.

9 La reforma del Código de Edificaciones fue sancionada por el Consejo Deliberante local en su sesión ordinaria del 14 de abril. Semanas después, el día 28 del mismo mes, es aprobada la ordenanza que introduce modificaciones al Código de Planeamiento Urbano. Para obtener mayores detalles acerca de los alcances de estas reformas véanse las ediciones impresas del diario El Día del 11, 25 y 29 de abril de 2010. 
empleados. Es así que se construyen de manera provisoria seis grupos de acciones bajo los rótulos: comunicación externa, comunicación interna, prácticas administrativas-institucionales, vinculación de asambleas, intervención directa en el escenario de la ciudad y elaboración de proyectos alternativos.

Comunicación externa: dos objetivos clave pueden sintetizarse en este grupo de actividades, concientizar a los vecinos e incorporar nuevos adherentes. Los mecanismos más utilizados fueron la recolección de firmas; puestos de difusión de la problemática en las principales esquinas de la localidad Arana y camino Belgrano y Arana y camino Centenario; difusión de la problemática puerta a puerta en la zona más cercana a la calle 403; realización de jornadas informativas para llegar al lugar donde cada uno vive, mediante charlas informales y la producción y circulación de mensajes tanto en medios gestionados por la organización, correos electrónicos, página web, grupos y perfiles de Facebook, como en medios masivos de comunicación locales, principalmente prensa escrita y programas de radio.

Comunicación interna: la construcción de una imagen común se presenta como una necesidad dentro del grupo que permitirá una mayor vinculación identitaria entre sus miembros y una identificación hacia el exterior. Los recursos más utilizados fueron la confección de carteles, remeras y globos para permitir una visualización del colectivo en cada una de las intervenciones en el escenario de la ciudad. La realización de asambleas es una de las instancias de comunicación medular. En ellas se acordaron los discursos colectivos, se tomaron decisiones por medio del voto directo, se promovieron herramientas de representación horizontal de todos los intereses y visiones. En este ámbito se buscó también compartir información, acordar próximas actividades, juntar fondos para solventar el trabajo, distribuir tareas y responsabilidades. A lo largo del tiempo, las asambleas tomaron un carácter rotativo para abarcar diferentes puntos del territorio de Villa Elisa. La plaza, el arco de camino centenario, las esquinas de Arana y Belgrano, el Club Curuzú y la biblioteca Alejo Iglesias fueron algunos de sus escenarios.

Prácticas administrativas-institucionales: el grupo buscó participar de todas las instancias institucionales para marcar su presencia y llegar a los diversos niveles de toma de decisiones políticas. Se participó, por ejemplo, en la audiencia pública organizada por Vialidad Nacional el 19 de noviembre de 2010. Por otra parte, se presentó un recurso de amparo en el Juzgado de Quilmes, se redactaron solicitadas con el fin de pedir una toma de posicionamiento a las autoridades municipales y provinciales y se gestionaron audiencias con diversos funcionarios de ambas jurisdicciones.

Vinculación de asambleas: con el objetivo de estrechar lazos con otras organizaciones de vecinos, que trabajan sobre problemáticas similares en la región, se pusieron en marcha instan- 
cias de encuentro y diálogo sobre el cuidado del espacio público y la calidad de vida. Se realizaron actividades en conjunto con ciudadanos de Abasto, quienes rechazaban la construcción de un basural, y se promovieron actividades junto a vecinos del barrio Dumon, que rechazan la instalación de antenas de telefonía celular.

Intervención directa en el escenario de la ciudad: bajo esta denominación se engloban las actividades de interrupción del tránsito en las arterias de circulación de la ciudad; estas tienen lugar en forma de cortes totales o parciales del camino Centenario, a la altura de la calle 403 y de la autopista Buenos Aires-La Plata. Al mismo tiempo, se encuentran otras acciones que visualizan al grupo, como las caravanas hacia el centro de La Plata, con destino final en la municipalidad, y las manifestaciones frente a la Casa de Gobierno. En estas dos últimas prácticas la circulación de vehículos no es interrumpida pero sí se busca llamar la atención de los conductores y transeúntes.

Elaboración de proyectos alternativos: en palabras de los vecinos, "una de las tareas por realizar es demoler cada uno de los argumentos de manera racional, esto significa racionalizar la protesta". Esta frase hace referencia a la discusión de las trazas posibles, poniendo en juego todo el capital cultural y el saber que la organización puede producir. En este caso, toma un lugar importante la presencia de profesionales, quienes promueven y diseñan las prácticas administrativas e institucionales mencionadas. Analizan las notas, programas y proyectos elaborados por los organismos competentes, y construyen propuestas alternativas con el objetivo de cumplir con actividades propositivas, que permitan al grupo influir en el diseño de la traza final. A lo largo del proceso de lucha se presentó la propuesta de concluir el tramo IV por la avenida 90 de la ciudad de La Plata.

\section{Comunicación/cultura: una mirada clave sobre las prácticas cotidianas de producción de sentidos}

Para abordar la problemática propuesta se tomaron diferentes decisiones, que guían el desarrollo del trabajo. En primer lugar, la investigación se inscribe en la línea de los denominados Estudios Latinoamericanos en Comunicación y Cultura. Esta perspectiva posibilita pensar la comunicación desde las prácticas cotidianas de los sujetos, ampliando la mirada tradicional que asociaba a esta disciplina solo con el estudio de los medios masivos de comunicación, sus lógicas de producción y sus discursos.

En líneas generales, esta mirada teórica permite preguntarse acerca del estudio de las mediaciones, la recepción y el consumo, la relación de la vida cotidiana con las tecnologías, las prácticas sociales y culturales, la constitución de las ciudades, los grupos sociales diferenciados, las minorías, los procesos micro y macrosociales que 
orientan y organizan la vida en las sociedades actuales. En consecuencia, admite focalizar en las agrupaciones que tienen un origen no institucionalizado y poseen características novedosas. Sobre este punto, es importante aclarar que todo acto nuevo trae consigo reconfiguraciones y recreaciones del pasado, por eso se prefiere hablar de un fenómeno novedoso antes que enteramente nuevo. En este sentido, se proponen incorporar los ya clásicos aportes de Raymond Williams (1997), que invitan a pensar estos procesos como combinaciones y cruces entre aspectos residuales y emergentes. De esta manera, surge la necesidad de desentrañar qué tienen de emergente y qué conservan de residual las organizaciones de vecinos autoconvocados. Al mismo tiempo, como se aclaró, se busca comprender a estas formaciones como herederas de instituciones de carácter cooperativo que hoy han perdido, en parte, esa función social, piénsese en clubes sociales, sociedades de inmigrantes, sociedades de fomento, bibliotecas populares y asambleas barriales.

Asimismo, el trabajo es enriquecido con aportes de otras disciplinas de las ciencias sociales, como la antropología urbana, la geografía social y la sociología de la cultura, perspectivas que posibilitan abordar el estudio de la ciudad como una construcción históricamente situada, poniendo un énfasis particular en los sujetos que la habitan y sus prácticas.
En este sentido, consideramos a la ciudad y al espacio público como escenarios en disputa, en el que emergen, se configuran y reconfiguran maneras de vincularse entre los sujetos. Escenarios dinamizados por relaciones de poder, que entretejen los diferentes actores involucrados, luchando, desde posiciones desiguales, por construir e instaurar un proyecto hegemónico. Se propone, entonces, pensar a la ciudad como:

el espacio donde se dan las principales prácticas culturales, las interacciones sociales cotidianas. Espacio para las interacciones, pero donde se gestan y ponen en juego los universos simbólicos: las identidades, las memorias, los saberes, las competencias (Reguillo, 1999, p. 30).

De este modo, se define a la ciudad como el lugar de la vida colectiva, el principal espacio de mediación del mundo individual en el social, donde la configuración y organización de sus espacios "forman la base material a partir de la cual pueden pensarse, evaluarse y realizarse una serie de posibles sensaciones y prácticas sociales" (Harvey, 2004, p. 86).

En la actualidad, las ciudades vienen experimentando un profundo proceso de reestructuración, bajo el impacto del cambio tecnológico, la urbanización acelerada y el avance de la globalización. Uno de los resultados de esta reestructuración se evidencia en las transformaciones del espacio público, es decir, los diferentes lugares en que "los ocupantes de las diversas zonas 
residenciales pueden encontrarse cara a cara, conversar, abordarse y desafiarse, reñir, discrepar o coincidir, elevar sus problemas particulares a nivel de asuntos públicos y hacer de éstos materia de interés particular" (Bauman, 2005, p. 31).

Desde esta perspectiva, el espacio público es concebido de una manera amplia, en oposición a la vieja concepción moderna que los asociaba solamente a extensos lugares verdes de esparcimiento, como plazas y parques. Una mirada histórica sobre este tema muestra, como afirma Liernur (2004), que las sociedades han cobijado de modo especial aquellas actividades que congregaban a sus miembros con finalidades de algún modo compartidas:

En este sentido no son menos "espacios públicos" las termas romanas que las estaciones ferroviarias y los bazares árabes, los templos y catedrales que las oficinas estatales y los estadios deportivos, porque en todos ellos se expresan o resuelven de algún modo necesidades compartidas (Leinur, 2004, p. 13).

El espacio público y la ciudad, entendida como un acontecimiento cultural y comunicacional (Silva, 2004; García Canclini, 1990), son el escenario en el cual se discuten los asuntos de interés público, "los nuevos modos de relacionarnos, integrarnos y distinguirnos en los lugares públicos que expresan la existencia de diversas matrices culturales cuyos actores participan activamente en la conformación de la cultura urbana" (Reguillo,
1999, p. 35). De ahí que las agrupaciones de vecinos autoconvocados, como V.A.V.E., permiten una aproximación a la trama urbana, poniendo énfasis en las disputas por la construcción de proyectos alternativos, donde se libran luchas, materiales y simbólicas, respecto de la ciudad que se desea construir y habitar.

Al mismo tiempo, las organizaciones autoconvocadas se convierten en lugares clave para poder observar y analizar la creación y recreación de lazos sociales en las ciudades actuales. Para comenzar a conceptualizar estas relaciones intersubjetivas, creemos que son de gran utilidad los aportes de René Millán (1994) para caracterizar a las nuevas organizaciones sociales. En sus investigaciones, el autor propone el término de "organizaciones voluntarias asistencialistas" para referirse a la formación de grupos u organizaciones de apoyo, que llevan adelante políticas sociales con modalidades muy heterogéneas y en inserciones institucionales diversas.

Millán sostiene que estas formaciones no son nuevas, pero cuando entra en crisis el Estado benefactor se produce una importante difusión de estas "microsolidaridades". Esta perspectiva busca romper con la lógica binaria que argumenta que son el Estado o el mercado los espacios a partir de los cuales se generan políticas de solidaridad. Desde el punto de vista del autor, estas miradas desconocen o desvalorizan apresuradamente las maneras de construir lazos de solidaridad de for- 
mas micro que, "sin ser nuevas, todas ellas presentan un carácter innovador en su función cultural, en la vinculación entre participación e individualidad y en su inserción en la estructura institucional" (Millán, 1994, p. 66). Los aportes realizados por Millán, contribuyen a agudizar la mirada acerca de los lazos que tejen los sujetos, el vínculo entre lo público y lo privado, así como a reforzar una mirada atenta sobre los rasgos innovadores y los entramados institucionales de las organizaciones autoconvocadas. Por otra parte, el autor ofrece una lectura crítica sobre el proceso de decadencia del Estado de Bienestar y las políticas sociales que lo caracterizaban.

Rosana Reguillo Cruz, en su obra La construcción simbólica de la ciudad (1999), designa a esas organizaciones bajo el nombre de "grupalidades", entendiéndolas como la emergencia de formas de agrupación social no partidarias y no institucionalizadas, que erosionan desde las márgenes del sistema, alterando las maneras de ejercicio del poder. Este fenómeno tiene lugar en un contexto en el cual, según afirma la autora, el sindicato, el partido, la asociación, aumentan como formas corporativas de control pero disminuyen como espacios de referencia y de adscripción. En paralelo a este proceso, "se asiste a la multiplicación de pequeños grupos que desbordan las categorías científicas en la medida en que no se inscriben en una racionalidad orientada y finalizada" (Reguillo, 1999, p. 88). Las grupalidades son de composición cambiante, de inscripción local y de estructura cotidiana, y tienden a interrelacionarse de manera horizontal, sin mediación del Estado, con otras colectividades.

Es innegable el aporte que implica la noción de grupalidades, al posicionar las agrupaciones en el entramado de las relaciones de poder (aspecto que no se observa en Millán). Se retoma, al mismo tiempo, su contribución para reflexionar acerca de las categorías analíticas con las que se cuentan, cuando las finalidades del encuentro no las propone una institución, sino la sociedad misma, de manera no institucionalizada. Por último, se rescata su mirada acerca de la política, comprendida más allá de la práctica o militancia partidaria.

En su análisis sobre las organizaciones políticas de la sociedad civil, Marcelo Leiras (2007) incluye a las "organizaciones que desarrollan estrategias respaldadas en argumentos de interés público para promover o resistir cambios sociales que, si se implementaran, entrarían en conflicto con los intereses o valores sociales, culturales políticos o económicos de otro grupo u organizaciones" (Leiras, 2007, p. 21).

El autor aporta una mirada política sobre los conflictos que cotidianamente se generan al entrar en pugna diferentes propuestas sobre temas que interesan a la opinión pública. En muchos casos, esas inquietudes son materializadas y visibilizadas desde 
las organizaciones de vecinos autoconvocados, quienes protagonizan disputas con otras instituciones y con el propio Estado.

Al analizar la conformación de las organizaciones contemporáneas, encontramos, en líneas generales, dos enfoques vigentes: por un lado, observadores que definen los encuentros sociales actuales como "resurgimiento", "re-emergencia", "renacimiento o reconstrucción". Por su parte, algunos analistas rechazan esas etiquetas, para ellos la ampliación de la "arena política" no es una reedición de patrones conocidos previamente sino un fenómeno en el que predominan los rasgos novedosos (Leiras, 2007).

Desde una posición que sigue la primera perspectiva se entiende a las configuraciones sociales y culturales como continuidades. En este sentido, se retoman los estudios de Raymond Williams (1997), que proponen comprender las complejas relaciones de poder, características del capitalismo avanzado, prestando atención a los elementos residuales, los componentes marginados de la tradición selectiva y los rasgos que se presentan como emergentes.

Esta línea nos permite acercarnos al fenómeno de las organizaciones autoconvocadas, comprendiendo que los procesos de construcción hegemónicos se dan por medio de la conexión de diferentes formas de lucha que van más allá de lo meramente político y económico.
Este ejercicio de revisar qué elementos del pasado y qué rasgos novedosos se observan en las organizaciones autoconvocadas abre el camino para el análisis de la creación y recreación de prácticas culturales y sociales vinculadas con la participación política. Se propone la categoría de formaciones como punto de partida para dirigir la mirada hacia esos espacios barriales y territoriales que se encuentran por fuera del entramado institucional tradicional, como los clubes sociales y deportivos, las sociedades de fomento o las sociedades de inmigrantes. Williams define a las formaciones como: "los movimientos y tendencias efectivos, en la vida intelectual y artística, que tienen una influencia significativa y a veces decisiva sobre el desarrollo activo de una cultura y que presentan una relación variable y a veces solapada con las instituciones formales" (Williams, 1997, p. 139).

Apropiarse de esta definición no es una tarea sencilla, se advierte un vínculo estrecho con las manifestaciones y tendencias artísticas e intelectuales. Sin embargo, comprender el arte, la cultura y las ideas con una mirada anclada en las relaciones de poder subyacentes permite adentrarse en el estudio de los procesos de lucha por la inclusión en la ciudad, procesos que se materializan tanto en el accionar de las instituciones como en los proyectos, programas y propuestas que emergen en espacios no instituidos formalmente, como las organizaciones de vecinos autoconvocados. 


\section{Referencias}

Acuña, C. H., y Vacchieri, A. (Comps.), La incidencia política de la sociedad civil. Buenos Aires: Siglo 21.

Bauman, Z. (2005). La globalización. Consecuencias humanas. Buenos Aires: Fondo de Cultura Económica.

Beck, U. (1998). ¿Qué es la globalización? Falacias del globalismo, respuestas a la globalización. Barcelona: Paidós.

Bonzi, L. (2010). Disputas territoriales en torno a la actividad minera en los valles Calchaquíes, Salta. El caso de la mina Don Otto en el departamento de San Carlos. En M. Manzanal y F. Villarreal (Orgs.), El desarrollo y sus lógicas de disputa en territorios del norte argentino. Buenos Aires: Ciccus.

Cáneva, V. (2010). Intersticios urbanos. La construcción de vínculos intersubjetivos en el espacio público platense. Ponencia presentada en las XIV Jornadas Nacionales de Investigadores en Comunicación "Investigación y Participación para el Cambio Social". Universidad Nacional de Quilmes Bernal, Argentina.

Cáneva, V., y Mendoza Jaufret, $\mathrm{H}$. (2007). Clubes platenses: al rescate de lo colectivo. Riesgos, desafíos y posibilidades de las instituciones barriales en la trama de la ciudad posmoderna. Tesis para obtener el título de licenciado en Comunicación Social con orientación en periodismo. Facultad de Periodismo y Comunicación Social, Universidad Nacional de La Plata, Argentina.
Cossani, A., y Duffard, M. (2007). Reflexión y acción en la Asamblea Barrial de Villa Elisa. Tesis para obtener el título de licenciado en Comunicación Social con orientación en periodismo. Facultad de Periodismo y Comunicación Social, Universidad Nacional de La Plata, Argentina.

Freidin, B., y Perrugoría, I. (2007). Construyendo la identidad del movimiento asambleario en contextos políticos cambiantes, una discusión teórico-metodológica. En R. Sautu (Comp.), Práctica de la investigación cuantitativa y cualitativa. Articulación entre la teoría, los métodos y las técnicas. Buenos Aires: Lumiere.

García Canclini, N. (1990). Culturas híbridas. Estrategias para entrar y salir de la modernidad. México: Grijalbo.

González Bombal, I. (1996). La visibilidad pública de las asociaciones civiles. Documento Cedes N. ${ }^{\circ} 116$. Buenos Aires: Centro de Estudios de Estado y Sociedad.

Harvey, D. (2004). La condición de la posmodernidad. Investigación sobre los orígenes del cambio cultural. Buenos Aires: Amorrortu.

Leinur, F. (2004). Apuntes sobre el espacio público en Buenos Aires. Privacidad, publicidad, incertidumbre. Revista TodaVia. Pensamiento y Cultura en América Latina, 9. Fundación OSDE, 10-15.

Leiras, M. (2007). La incidencia de las organizaciones de la sociedad civil en las políticas públicas. En C. 
Acuña y A. Vacchieri (Comps.), La incidencia política de la sociedad civil. Buenos Aires: Siglo XXI Editores.

Millán, R. (1994). Solidaridad y producción informal de recursos. En Solidaridad: recurso o valor. México: Universidad Nacional Autónoma de México.

Pírez, P. (Octubre-diciembre de 1995). Actores sociales y gestión de la ciudad. Ciudades, 28. México: RNIU.
Reguillo Cruz, R. (1999). La construcción simbólica de la ciudad. Sociedad, desastre y comunicación. México: Iteso.

Silva Téllez, A. (2004). Imaginarios urbanos: hacia el desarrollo de un urbanismo desde los ciudadanos. Bogotá: Convenio Andrés Bello.

Williams, R. (1997). Marxismo y literatura. Barcelona: Península. 